\title{
Introduction to the Handbook of Research Methods on Gender and Management
}

\author{
Valerie Stead, Carole Elliott and Sharon Mavin
}

The motivation for this Handbook is to provide an essential resource for researchers in gender and management, and for those in other fields of study including adult education, leadership, culture, media and politics. Gender and management research is challenging, conducted in a wide range of geographical and organisational contexts, approached from individual, organisational and social levels of analysis. In this Handbook, contributing authors are unified in understanding gender as a complex, dynamic, socially constructed phenomenon, (re)created through processes and practices that maintain difference. This understanding brings attention to the ongoing 'doing' of gender, and how it is socially situated in our everyday practice, including in organisational and workplace contexts. Typically focused upon deeply embedded social issues and structural inequalities, gender and management research is concerned to make these issues and inequalities explicit within a particular socio-cultural and political context, and to provide understandings of how and why they persist in order to inform action for change. Gender and management scholars therefore require a repertoire of methodologies and methods capable of getting under the surface of everyday discourses, practices and processes, organisational routines and systems to access how gender organises, shapes, operates and influences. Evidencing the broad reach and fundamental importance of gender and management research, contributors to the Handbook are internationally diverse and draw on multiple disciplines in their research. These include management; leadership; organisation studies; public administration; sport; critical policy; entrepreneurship; accounting; sociology; cultural studies; adult education; ethics; philosophy; human resource development; media studies; and science and technology studies.

The Handbook encompasses methodologies and methods that probe, explore and unearth gendered behaviours, interactions, systems, processes and practices. These include methods and approaches rarely utilised in gender and management research such as oral history, institutional ethnography, and quantitative methods for mining large volumes of data. Our categorisation of chapters emphasising either the autoethnographic, practical, critical or methodological acknowledges a primary focal point in each of the studies. However, we recognise that this is by no means a perfect categorisation and that the chapters, reflective of the multiplicity of gender and management research, may easily span different categories. Nonetheless, we hope this categorisation, and the acknowledgement of their interconnections, is helpful in recognising how gender and management research cannot work in isolation from the broader socio-cultural context, but must continually strive to challenge, question and call to account the wider systems in which we work and live. 
In line with our aim to provide an essential resource of methods, contributors explain the method or approach they adopt, and identify its origins and relevance to gender and management research. Contributors provide exemplars and discuss the challenges and opportunities that the method presents in the study of gender and management, drawing attention to ethical implications.

There is a focus on methods that help researchers situate themselves and their studies, and that develop knowledge that can push forward new directions and understandings for gender research more broadly. Reflecting such situatedness in research and context, autoethnography in qualitative studies in gender and management is covered in Part I 'Autoethnographic Methods' and is also a thread in other section chapters. Parts II, III and IV include chapters that focus on practical approaches, critical approaches and a final section outlining methodological developments.

\section{PART I: AUTOETHNOGRAPHIC METHODS}

This first section of the Handbook consists of three chapters that interpret and apply autoethnographic methods to experiences the authors have encountered. The autoethnographic method enables authors to connect a personal experience to processes and structures in the wider social context. When we approached potential authors to ask them if they would be interested in contributing a chapter to the Handbook it soon became apparent that autoethnography is increasingly regarded as a method particularly suited to documenting the experiences of individuals who have been largely ignored by the management studies field.

Chapter 1 by Juanita Johnson-Bailey positions autoethnography amongst the range of interpretive methods available within qualitative research. Acknowledging the criticisms levelled at autoethnography as a method of scholarly inquiry, Johnson-Bailey nevertheless argues that it holds a unique and progressive position due to the self-critique and reflexivity it encourages researchers to practise. Autoethnography stands at the intersection of the personal and the political, and has been used as a method to study gender by researchers taking an oppositional approach to their social-cultural condition. The method allows Johnson-Bailey to examine gender's relationship to race, drawing attention to how the intersection of gender with race operates hierarchically in her experiences as a black woman.

Chapter 2 by Saoirse O'Shea begins with the reminder that in management studies ethnographic studies of others' working lives are presented as realist accounts that largely fail to recognise gender's organising influence. O'Shea explains that autoethnography is important for management studies as it provides an emotional account. This is significant if the field of management studies is to recognise its empirical limitations, particularly with regard to the experiences of minority groups in organised settings. Autoethnography permits a wider range of individual experiences to be heard, allowing women and minorities to 'speak truth to power' about their marginalisation within patriarchal and phallocentric settings. 
The setting for Chapter 3 by Allan Discua Cruz, Eleanor Hamilton and Sarah L. Jack is a family business in Honduras. In contrast to Johnson-Bailey's and O'Shea's chapters, this autoethnography daws on Discua Cruz's experience of the practice of primogeniture in family business succession processes. The interpretation process follows Ellis et al.'s (2011) suggestion to write retrospectively, and the focus on examining the performance of gender identity involves Hamilton and Jack working with Discua Cruz to interpret his experience. The chapter describes how autoethnography can be applied within family business as a method to examine either personal or professional experiences, and the different tools that can be used to do this, including journaling, drawings, photographs and letters.

\section{PART II: PRACTICAL APPROACHES}

The chapters in Part II place a primary focus on issues related to practical aspects of conducting gender and management research. Through these practical approaches, such as the conduct of interviews, the development of action learning groups and the facilitation of focus groups, the authors offer critical insights into the design and dynamics of gender and management research. Two broad concerns connect the chapters. First, the concern of accessing what Hanold terms 'the important but not easily described' in her chapter on focus groups, and connecting these to broader organisational and social practices and discourse. Second, attention to the relational and situated nature of gender and management research, both in consideration of the roles and the relationship between researcher and research participant, and in research design including in the use of quantitative methods.

In Chapter 4, Maylon Hanold proposes focus groups as a method to enable emergence of deeper meanings of why individuals adopt a particular perspective. Revealing how individuals construct meaning around those perspectives enables the connection of individual experience to larger social constructs. The exemplar of focus groups, utilised on a graduate sports programme to gain insight into the complex gendered phenomenon of confidence, provides the context for a detailed practical guide. Hanold outlines both challenges and opportunities of the focus group method, and the importance of attending to ethical issues of confidentiality and participant contribution.

Chapter 5 by Hannah Dean and Lorna Stevenson presents oral history method as a critical feminist method to access experience, and to challenge dominant discourse by giving voice to those marginalised by society. Through two separate UK studies, of female entrepreneurs and of accounting professors, the authors provide extensive detail to guide the researcher in the process, including considerations from planning stages through to data collection. The chapter covers multiple techniques including deep listening and sharing authority, and important ethical and legal implications of accessing oral history archives.

In Chapter 6, Rita Gardiner, Jennifer Chisholm and Hayley Finn continue the theme of connecting everyday experience to broader structural concerns to wider 
discourse. Presenting institutional ethnography (IE), a mode of inquiry developed by Dorothy Smith (1987), they draw attention to how institutional relations are mediated by texts and processes. In particular, they highlight the conceptual framework of 'relations of ruling' as a means to reveal overarching structures that organise and influence working life. The chapter provides an example of utilising IE by mapping sexual violence policy and process across two higher education institutions in Canada, noting ethical implications including sensitivity to complexities of language, and how it can exclude.

Turning to the intersubjective interplay between researcher and participant, Chapter 7 by Farooq Mughal, Valerie Stead and Caroline Gatrell presents participant observation as a method to gain understanding of the situated nature of gender and cultural relations. The authors examine key features of participant observation relevant to gender and management researchers, and reflect on research conducted across three Pakistani business schools, to demonstrate how participant observation requires the researcher's negotiation of cultural politics and gender. Examples illustrate how this negotiation shapes the design and organisation of participant observation, and adds to knowledge about gender and cultural politics, and power dynamics. Challenges are presented, including ethical concerns of cultural sensitivity and participants' psychological safety.

Chapter 8 by Patricia Lewis also examines issues of power between researcher and participant. Analysing the dynamics of power relations within interview encounters, Lewis draws on her experience of interviewing women and men leaders in the City of London to challenge the view that interviewers hold the position of power in such meetings. She adopts the concepts of encounter and postfeminism to understand interviews with 'elite' participants as a theoretical as well as a practical task. Outlining the different subject positions she found herself called into during the interviews, Lewis' theorisation of the interview process highlights the fluidity of power dynamics, including the constant adjustment of masculine and feminine behaviours, during interview encounters.

Chapter 9 by Jouharah Abalkhail takes an 'insider research' perspective to explore the researcher's role. Unlike outsider research, more commonly aligned to objective study, Abalkhail depicts the insider researcher as 'at-home'; someone situated within, and an active participant in the cultural setting under study. Focused on two studies of Saudi women's career experiences, the chapter details opportunities afforded to the insider researcher, including shared knowledge and cultural values. Equally, Abalkhail describes practical and ethical challenges of managing researcher positionality, and being open to scrutiny regarding interpretation and validity of findings. Accordingly, Abalkhail recommends researchers adopt a reflective and reflexive stance, reflecting in practice as well as on practice.

Part II concludes with two chapters that focus on quantitative methods, noting the scope for gender and management scholars to examine numerical data, existing datasets and large volumes of data that remain relatively unexplored in gender and management research. In Chapter 10, Anne Laure Humbert and Elisabeth Guenther examine the opportunities afforded by quantitative methods more broadly. 
Responding to challenges levelled at positivism by gender scholars, Humbert and Guenther make the case for drawing on feminist ontology and epistemology to inform gender aware design and analyses so that research does not overlook or reproduce inequalities. Adopting a feminist purpose and drawing on gender expertise (that is, in-depth understanding of and engagement with feminist research including gendered, racialised and classed structures, institutions and processes), Humbert and Guenther use linguistic theory processes of denotation and connotation to illustrate how different forms of quantitative data can be harnessed to bring about social change.

In Chapter 11, Aaron Page and Ruth Sealy focus on a specific quantitative method. They present a step by step guide to topic modelling as a means to access and analyse increasingly large volumes of gender diversity data. Illustrated through an examination of the content of gender diversity statements in American organisations, they demonstrate how the technique can be used on text-rich data to reveal how organisations construct, manage and communicate gender. Taking into account the need for human interpretation and input at each stage of the process, Page and Sealy recommend applying standards of practice for qualitative research to ensure validity and consistency.

Chapters 10 and 11 both offer ethical considerations, emphasising the need to remain critical regarding tacit biases.

\section{PART III: CRITICAL APPROACHES}

While all of the chapters in this volume assume a critical approach in that they are concerned to give voice to those who are marginalised or excluded from mainstream discourse, the chapters in Part III differ in drawing on theoretical perspectives more commonly associated with other disciplinary fields. These perspectives adopted by the contributing authors are purposeful in enabling the gender and management scholar to challenge taken for granted assumptions and to reveal asymmetric social relations.

In Chapter 12, Mark Gatto and Jamie Callahan propose dystopian fiction (DF) as a lens for critical discourse analysis (CDA), in order to gain greater insight into gendered power discourses, and to identify the potential for resistance or change. Enabling the illumination of how language is used in narratives and storytelling to reflect such discourses, this approach draws attention to how ideology is (re)produced through language. Gatto and Callahan provide detailed exemplar cases utilising the narratives of working parents, and outline the formulation of guiding concepts and theories from DF tropes to inform data collection and analysis. Ethical implications are considered including the need to maintain participants' trust and confidentiality.

Chapter 13 by Anita Biressi draws on the work of Roland Barthes to explore the use of semiotic analysis as a set of critical tools to illuminate gendered power relations in the corporate world, and whether they are challenged in the public sphere. The chapter outlines how semiotic analysis examines the processes by which mean- 
ings are produced, circulated and understood, by revealing what is often implicit or masked in media texts and imagery. Through an illustrative case study drawing on the media depiction of British investment fund manager Nicola Horlick, Biressi analyses the myth-making of the corporate superwoman. Discussing the benefits and limitations of the method, the chapter highlights particular ethical considerations in organising and framing the analysis.

In Chapter 14, Mayra Ruiz Castro reminds us of reflexivity and intersectionality's centrality to feminist thought and how these concepts are valuable to autoethnography. She suggests that combining these concepts to create the concept of intersectional reflexivity can strengthen autoethnography as a critical method to interrogate both privileges and disadvantages attached to the researcher. Drawing on her experiences as a dark-skinned professional woman in Mexico and a foreign woman of colour working in UK higher education, Ruiz Castro alerts us to how attention to intersectional reflexivity in autoethnographic accounts lends a richness to interpretations that have remained largely hidden in management studies.

\section{PART IV: METHODOLOGICAL DEVELOPMENTS}

Part IV provides readers with approaches to methodology in terms of supplying overarching or contextual frameworks for research into gender and management. We did not set out to cover methodology but its importance to gender research cannot be underestimated. The nature of gender research can lead researchers to combine methodology and method as principles of the research approach or to approach these separately.

Part IV begins with Chapter 15 by Alexia Panayiotou, which inspires the use of visual methodology and methods for gender and management research. The chapter provides a plethora of research methods and sites where this methodology can be operationalised to develop deeper understandings of gender and management. This chapter highlights how visual research extends our ways of knowing and enables us to study 'elusive knowledges' (Toraldo et al. 2018) such as gender, and considers how visual methodology and methods requires researcher self-reflexivity. There is comment on the challenges in analysing and especially producing visual material, and explicit discussion of the power issues involved and how it is important to integrate visual methodologies with feminist epistemologies.

Chapter 16 by Cécile Guillaume and Sophie Pochic outlines how a methodology based on the interactionist concept of career enables a comprehensive, situated, multi-space and dynamic understanding of women's career development. This career methodology enables investigation of different organisational and individual processes reproducing gender inequalities in union leadership positions, while uncovering the equality/diversity policies that have enabled progress. The authors draw on a comparative research project of four unions in France and the UK. The chapter utilises the career methodology through qualitative interview methods and explains how to analyse using biographical tables (work, family, union activities) 
with specific attention given to 'turning points'. Ethical issues and suggestions of how to overcome these are also provided.

Chapter 17 by Joshua Collins and Jeremy Bohonos considers phenomenology and autoethnography as mechanisms for understanding and explaining masculinity. They usefully provide an overview to the historical and current state of masculinity, including toxic masculinity, masculinity, gender identity and expression, masculinity and sexual orientation, and masculinity and race. The chapter explains feminist and queer phenomenology and introduces post-intentional phenomenology. This moves from qualitative interview methods to include the researcher who contributes data alongside participants. Various approaches to autoethnography are covered, along with the need for positionality in relation to their own intersectionality. The chapter raises ethical issues for researchers to take into account.

The final two chapters in Part IV mobilise feminist posthumanist philosophy in the context of gender research. Lara Pecis' chapter provides an illustration of how concept as method can act as a political force for revealing the making of sexual differences, as well as bringing to the fore the politics of production of ethnographic research. Natasha Mauthner and Sophie Alkhaled explore the performative effects of a diffractive methodological practice of the Listening Guide, as an object of study in its own right.

Chapter 18 by Lara Pecis is based on reflections on using concept as method. The chapter illustrates how materialities and meanings are constituted in knowledge production through the analysis of a piece of ethnographic work with researchers in a pharmacological institute. This includes how a turn to concepts rather than phenomena shakes the foundations of gender and management research so that researchers engage in concept as method as an embodied reading and writing of 'real' events. There is illustration of how the making of sexual differences is performed in the interview and observations process which is valuable for gender and management research.

Chapter 19 by Natasha Mauthner and Sophie Alkhaled focuses upon a feminist posthumanist diffractive methodology. Following posthumanist inquiry, researchers are aware that the objects of study they give rise to must be accounted for, not taken as given, and through a feminist posthumanist approach, a diffractive methodology is understood as an inherently ethical practice. The chapter outlines the Listening Guide method by analysing stories of 13 female entrepreneurs in Saudi Arabia. Practically, guiding questions are provided as a means of studying gender and management without taking this as ontologically given.

Together, the chapters in this book illustrate the breadth, depth and reach of gender and management research. A constant thread connecting the chapters is the methodological challenge to capture the complex interplay between individual, organisation and management, and broader social relations. The variety of methods and methodological approaches presented in this book illustrates the opportunities available for gender and management scholars to gain critical insights that reveal this complexity and that advance our knowledge, and importantly, reveal potential for change. As 
the gender and management research agenda continues to expand and to gain greater prominence in uncovering and calling to account persistent inequalities, these chapters offer a rich basis from which to develop further methodological knowledge and innovations.

\section{REFERENCES}

Ellis, C., T. E. Adams and A. P. Bochner (2011), 'Autoethnography: an overview', Historical Social Research/Historische Sozialforschung 36(4 (138)), 273-90.

Smith, D. E. (1987), The Everyday World as Problematic: A Feminist Sociology, Toronto: University of Toronto Press.

Toraldo, M. L., G. Islam and G. Mangia (2018), 'Modes of knowing: video research and the problem of elusive knowledges', Organizational Research Methods, 21(2), 438-65. 